\title{
Developing a Traffic Management Framework for Coastal Expressway Bridges under Adverse Weather Conditions: Case Study of Rain Day in Shenzhen, China
}

\author{
Chenming Jiang, ${ }^{1}$ Jian John $\mathrm{Lu}^{2}{ }^{2}$ Yuming Jiang, ${ }^{2}$ Xiaonan Cai, ${ }^{1}$ and Anning $\mathrm{Ni}^{3}$ \\ ${ }^{1}$ Transportation Research Center, School of Naval Architecture, Ocean and Civil Engineering, Shanghai Jiao Tong University, \\ Shanghai 200240, China \\ ${ }^{2}$ The Key Laboratory of Road and Traffic Engineering, Ministry of Education, School of Transportation Engineering, Tongji University, \\ Shanghai 201804, China \\ ${ }^{3}$ Department of Transportation, Shipping and Logistics, School of Naval Architecture, Ocean and Civil Engineering, \\ Shanghai Jiao Tong University, Shanghai 200240, China \\ Correspondence should be addressed to Yuming Jiang; 2008jet@sina.com
}

Received 13 May 2015; Accepted 8 July 2015

Academic Editor: Daniele Fournier-Prunaret

Copyright (c) 2015 Chenming Jiang et al. This is an open access article distributed under the Creative Commons Attribution License, which permits unrestricted use, distribution, and reproduction in any medium, provided the original work is properly cited.

\begin{abstract}
Adverse weather can reduce visibility and road surface friction, lower vehicle maneuverability, and increase crash frequency and injury severity. The impacts of adverse weather and its interactions with drivers and roadway on the operation and management of expressway or expressway bridges have drawn the researchers' and managers' attention to develop traffic management frameworks to mitigate the negative influence. Considering the peculiar geographical location and meteorological conditions, the Guangshen Coast Expressway-Shenzhen Segment (GSCE-SS) was selected as a case in this study to illustrate the proposed traffic management framework on rain days. Conditions categorized by rainfall intensity and traffic flow were the main precondition to make the management decisions. CORSIM simulator was used to develop the alternate routes choice schemes, providing reference for other systems in the proposed traffic management framework. Maps of (a) entrance ramp control (ERC) strategies; (b) mainline control strategies; (c) alternate routes choice; (d) information release schemes, under scenarios of different volume and rainstorm warning grades (BLUE to RED), were drawn to present a reference or demonstration for managers of long-span expressway bridges not only in China, but even in the world.
\end{abstract}

\section{Introduction}

On account of the overwhelming majority of transportation modes being directly exposed in the atmospheric environment, the total process of traffic activity is inevitably more or less subject to weather conditions such as precipitation, snow, fog, high winds, and extreme temperatures.

Various impacts of weather and related events on the roadway environment and surface transportation systems have been summarized by researchers, as listed in Table 1 [1]. Adverse weather events impose negative effects upon roadway environment by reducing visibility, pavement friction, and vehicle stability and maneuverability, upon transportation system by decreasing roadway capacity and operation speeds and increasing delay, speed variability, and accident risk. Besides, adverse weather can also disrupt access to roads (e.g., lane obstruction or submersion and pavement buckling) and damage road infrastructure (e.g., traffic control devices and communications systems) [2] and to some extent affect traffic volume by disturbing individuals' predetermined travel schedule [3].

Because of the impact of adverse weather on decreasing roadway capacity, the most intuitional outcome is lowering the operation speed and arousing travel delay. Travel time delay on arterial roads increased by $11 \%$ in wet pavement conditions [4] and by more than $12 \%$ in the presence of precipitation, high winds, low visibility, or slick pavement [5]. Travel time increased by as much as 50\% during extreme weather events, such as widespread snowstorms [6]. 
TABLE 1: Weather impacts on roadway environments and transportation systems.

\begin{tabular}{|c|c|c|}
\hline Weather events & Roadway environment impacts & Transportation system impacts \\
\hline Rain, snow, sleet, hail, and flooding & $\begin{array}{l}\text { (i) Reduced visibility } \\
\text { (ii) Reduced pavement friction } \\
\text { (iii) Lane obstruction and submersion } \\
\text { (iv) Reduced vehicle stability and } \\
\text { maneuverability } \\
\text { (v) Increased chemical and abrasive use for } \\
\text { snow and ice control } \\
\text { (vi) Infrastructure damage }\end{array}$ & $\begin{array}{l}\text { (i) Reduced roadway capacity } \\
\text { (ii) Reduced speeds and increased delay } \\
\text { (iii) Increased speed variability } \\
\text { (iv) Increased accident risk } \\
\text { (v) Road/bridge restrictions and closures } \\
\text { (vi) Loss of communications/power services } \\
\text { (vii) Increased maintenance and operations } \\
\text { costs }\end{array}$ \\
\hline High wind & $\begin{array}{l}\text { (i) Reduced visibility due to blowing snow or } \\
\text { dust } \\
\text { (ii) Lane obstruction due to windblown debris } \\
\text { and drifting snow } \\
\text { (iii) Reduced vehicle stability and } \\
\text { maneuverability }\end{array}$ & $\begin{array}{l}\text { (i) Increased delay } \\
\text { (ii) Reduced traffic speeds } \\
\text { (iii) Road/bridge restrictions and closures }\end{array}$ \\
\hline Fog, smog, smoke, and glare & Reduced visibility & $\begin{array}{l}\text { (i) Reduced speeds and increased delay } \\
\text { (ii) Increased speed variability } \\
\text { (iii) Increased accident risk } \\
\text { (iv) Road/bridge restrictions and closures }\end{array}$ \\
\hline Extreme temperatures and lightning & $\begin{array}{l}\text { (i) Increased wild fire risk } \\
\text { (ii) Infrastructure damage }\end{array}$ & $\begin{array}{l}\text { (i) Traffic control device failure } \\
\text { (ii) Loss of communications and power services } \\
\text { (iii) Increased maintenance and operations } \\
\text { costs }\end{array}$ \\
\hline
\end{tabular}

More importantly, the immense economic loss and casualties caused by traffic crashes which result from low pavement friction, poor vehicle maneuverability, and deficiency of visibility have long been what the highway management departments and traffic researchers are caring about. According to a research by Booz Allen Hamilton, based on NHTSA data, on average, 6,250 people are killed and over 480,000 people are injured in weather-related crashes in the US and the vast majority of most weather-related crashes happen on wet pavement and during rainfall: seventy-four percent $(74 \%)$ on wet pavement and forty-six percent (46\%) during rainfall ("weather-related" crashes are those that occur in the presence of adverse weather and/or slick pavement conditions).

Thus, the management departments of freeway or the national highway administrations all around the world have spared no effort to devote themselves to mitigating the negative influence of adverse weather on traffic operation safety and levels of service, by developing kinds of systematic traffic management strategies for adverse weather invents. Due to the high operation speed and mass flow on expressway, some adverse-weather-induced incidents may result in either severe crashes or large-scale congestion and delay.

The purpose of this study is to develop a traffic management framework for coastal expressway bridges under adverse weather conditions. In particular, kinds of adverse weather invents are analyzed together due to their similarity in disaster-causing mechanism, but the impact of rainfall on the management of Guangshen Coastal Expressway-Shenzhen Segment is selected as a case study to explore the systematization of traffic management in this research.

\section{Literature Review}

2.1. Capacity and Speed Reduction. The Highway Capacity Manual (2000) [7] declares that adverse weather can significantly reduce capacity and operating speeds. Chapter 22 in the manual provides information regarding speed and capacity reductions due to rain or snow of light and heavy intensities. The manual recommends between $0 \%$ and $15 \%$ reductions in capacities and $2 \%-14 \%$ and $5 \%-17 \%$ reductions in speeds due to light and heavy rains, respectively.

Speeds may be not affected by wet pavement until visibility is affected, which suggests that light rain does not decrease operating speeds but heavy rain does and can produce a prominent effect on traffic flow [8]. Similarly, Ibrahim and Hall [9] concluded that light rain and snow resulted in similar reductions in speeds $(3 \%-5 \%)$, but heavy rain caused $14 \%$ $15 \%$ and heavy snow caused $30 \%-40 \%$ reductions in speeds, compared to clear and dry conditions. Although they defined rain and snow in light and heavy categories, they did not specify intensity ranges within these categories, neither does the HCM 2000.

Smith et al. [10] investigated the impact of rainfall, at varying levels of intensity, on freeway capacity and operating speeds. Rainfall was classified into light rain (0.01 to 0.25 inches/hr, i.e., 0.25 to $6.4 \mathrm{~mm} / \mathrm{hr}$ ) and heavy rain (greater than 0.25 inches/hr, i.e., $6.4 \mathrm{~mm} / \mathrm{hr}$ ). Capacity reduction was evident and statistically significant with the increase of rainfall intensity. Light rain decreases freeway capacity by $4-10 \%$. Heavy rain decreases freeway capacity by $25-30 \%$. Under the same rainfall intensity classification criteria, the presence of rain, regardless of intensity, results in approximately a $5.0-6.5 \%$ average decrease in operating speeds whose means 


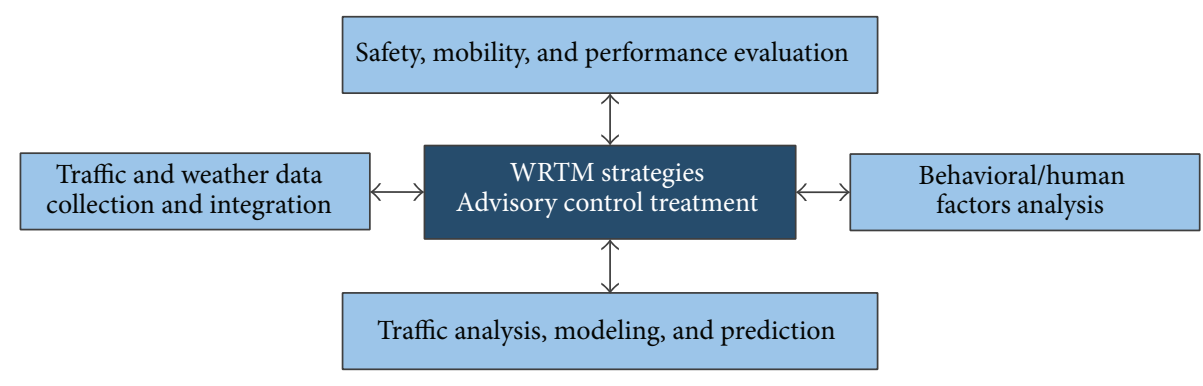

FIGURE 1: Framework for Weather Responsive Traffic Management (WRTM) Program [15].

are all greater than $55 \mathrm{mph}$, that is, $88 \mathrm{~km} / \mathrm{hr}$. Prior research $[10,11]$ indicated similar results for reductions in freeway capacities due to light rain conditions but showed lesser reductions in capacity $(10 \%-17 \%)$ than the reductions of $25 \%-30 \%$ obtained by Smith et al. [10]. The study conducted by Agarwal and Maze [12] found that light rain (0.01-0.25 inches/hour) has a significantly greater impact (5\%-10\%) on capacity, as opposed to no reductions mentioned in the Highway Capacity Manual 2000. On the other hand, because that high frequency of crashes on adverse weather days can always result in large-scale disorder at expressway and considerable pressure for operation management, to propose a traffic management framework that can be utilized by expressway managers under adverse weather is an indispensable and pressing need.

\subsection{Weather Responsive Management Program or System for} Highway. Weather is the second largest cause of nonrecurring congestion, the unexpected congestion that frustrates even the calmest drivers. Weather, which accounts for 25 percent of all delays, is also costly. Close to 1 billion hours are lost in the US each year due to weather-related delays [13].

The Federal Highway Administration (FHWA) Road Weather Management Program (RWMP) has long been devoting efforts into improving traffic operations and safety under adverse weather conditions. Weather Responsive Traffic Management (WRTM) is the central component of the program's efforts. WRTM includes using weather forecasting to provide proactive advisories as well as control strategies based on forecasts of weather conditions prior to the impacts of those conditions on traffic. WRTM also brings together into a logical framework various other activities (such as weather information integration, traffic analysis, and performance measurement) that the RWMP has been supporting. WRTM is not a single strategy per se but a combination of techniques, tools, and systems that transportation authorities can use for mitigating the impacts of weather on their operations [14]. The framework for WRTM Program is shown in Figure 1 [15].

\section{Traffic Management Framework for Expressway Bridges}

In this section, a traffic management framework for expressway bridges (TMFEB) under adverse weather conditions is proposed. Figure 2 illustrates the detailed contents of TMFEB. The leftmost column includes the data required or input, and the rightmost column includes exporting schemes or control measures.

Traffic Demand Analysis aims at the travel demand and the utilization rate of the objective roadway (i.e., GSCE-SS in this study). The AADT or ADT, the heavy goods vehicle (HGV) ratio, and volume distribution in each hour of the day are analyzed. In particular, volume on weekend and some important festivals should be given more attention. Then the traffic demand and its variation law could be well understood.

Traffic Network Analysis focuses on the physical features and the capacity (traffic supply) of the roadway network where the objective roadway is. Traffic management strategies include traffic control system, alternate routes system, and information release system. Traffic control system consists of primary control measures such as mainline control, entrance ramp control, reversible lane control, and variable speed limit. Alternate routes system provides the evacuation solutions (diverging points and routes) under different adverse weather and flow conditions. Advisory strategies integrate two parts: (1) all timely, effective, and accurate information released by the authority and (2) all appropriate media channels and publicity means (information release system) to guide the motorists in travel choice and their driving behavior.

\section{Case Study}

In this section, the TMFEB is further described based on the case study of the Guang-Shen Coastal Expressway-Shenzhen Segment (GSCE-SS). The location of the GSCE-SS in Pearl River Delta Region (PRDR) is shown in Figure 3.

Guang-Shen Coastal Expressway (GSCE) is not only a vital transportation passageway connecting Hong Kong on the south in the PRDR but also a key component of the National Expressway Network of China. The GSCE consists of three segments from the north to the south: the Guangzhou Segment, the Dongguan Segment (GSCE-DS), and the Shenzhen Segment. The overall length of the GSCE-SS is up to 30.445 kilometers, with 6 interchanges, 16 long-span bridges, and 5 toll stations along the line. The GSCE-SS is designed as a bidirectional eight-lane roadway with a $100 \mathrm{~km} / \mathrm{h}$ designing speed. Up to $99.6 \%$ of the GSCE-SS is constructed over the water as bridges or viaducts, so it is worthy of the name “expressway bridge." 


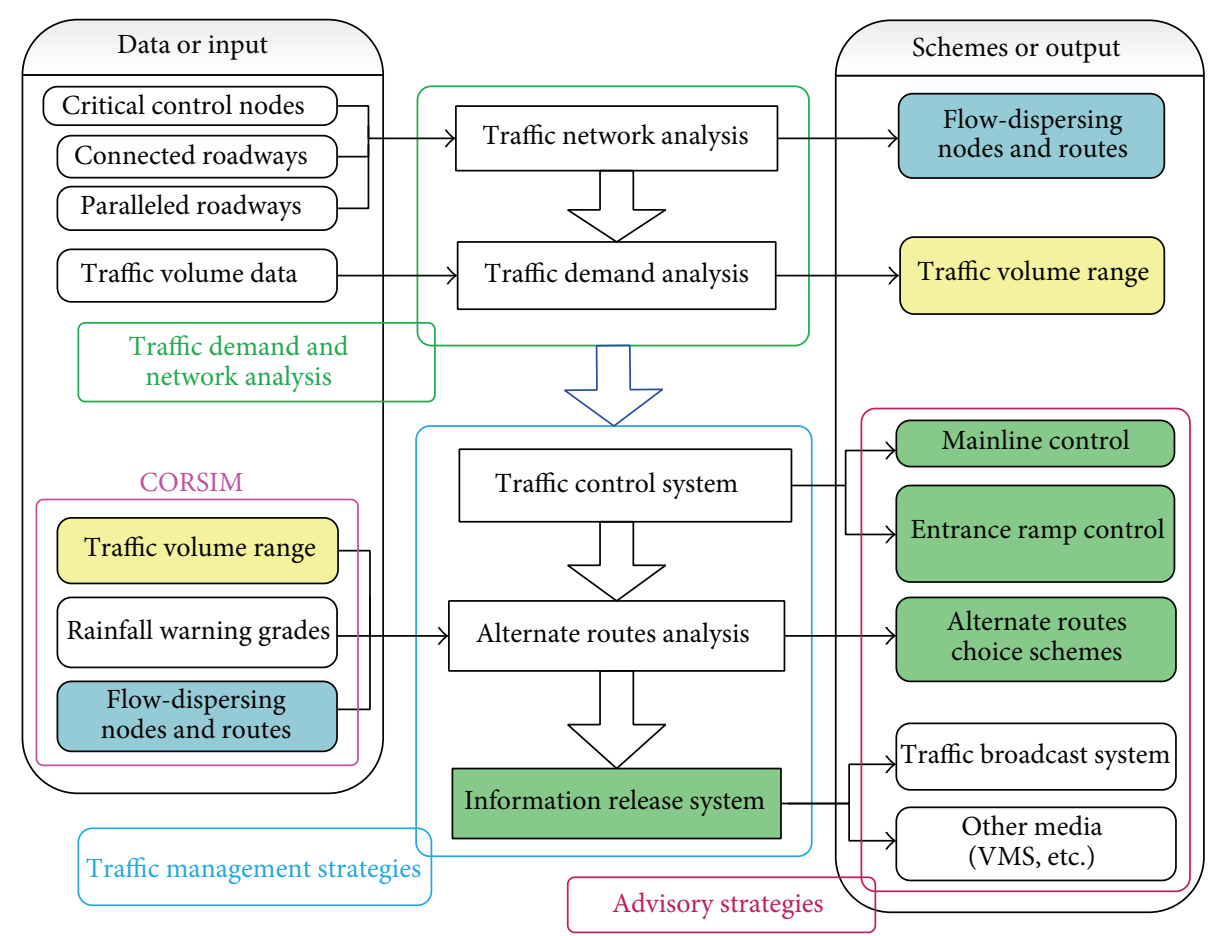

FIGURE 2: Framework for the proposed traffic management system under adverse weather events.

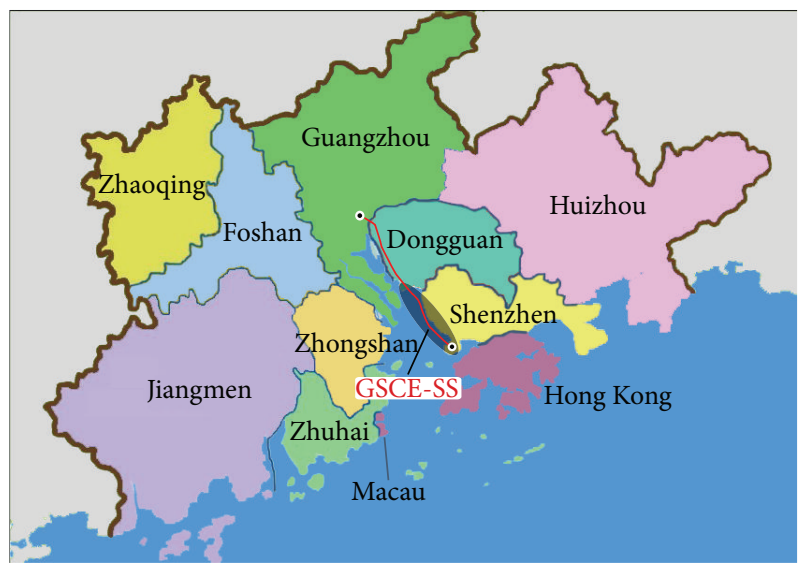

FIgure 3: The location of GSCE-SS in Pearl River Delta Region.

4.1. Climate Conditions. The GSCE-SS is an expressway constructed over outer sea of western Shenzhen which turns out to be a mixed terrain composed of lands, sea, and shallows. The hydrogeological conditions are complex and the climate is inclement. Shenzhen has a subtropical maritime monsoon climate with a high occurrence frequency of adverse weather, such as rainstorm, typhoon, and fog.

4.2. Traffic Demand Analysis. The opening of GSCE-DS to traffic on December 28, 2013, signified that the new alternative route-GSCE for driving between Guangzhou and Shenzhen was totally unimpeded. Combining the traffic volume data acquired from our field survey with data provided by the Shenzhen Highway Company Limited in the past eight months, the hourly traffic volume of the GSCE-SS ranges from 3,400 to 5,600 vehicles, and the percentage of HGV is about $6.1 \%$. Based on our field survey, the reason for the overestimated utilization ratio of the GSCE-SS may lie in the insufficiency of publicity, the ambiguity of the fixed signs indicating on- and off-ramp, and the hidden new roadway on the vehicle navigation system.

4.3. Traffic Network Analysis. Ju et al. [16] designed the Integrated Motorist Information Systems (IMIS) to encourage mainline motorists upstream of traffic incident to use an alternate route to bypass the incident site. Similarly, in the management of GSCE-SS, if the capacity of GSCE-SS is sharply decreased on account of adverse weather, to choose an alternate inland route whose capacity is not largely affected will be doubtlessly an advisable decision, but the key problem lies in the timeliness and accuracy of motorist receiving the information and effective guidance.

4.3.1. Paralleled Roadways. Considering the fact that choosing lower-level roadways in Shenzhen probably has problems of roads connection and capacity deficiency, only those national/provincial freeways or municipal highway with high capacity and accessibility are considered as alternate routes. So excluding the GSCE-SS which is the object being studied, three paralleled roadways were chosen as alternate routes as follows:

(i) Shenzhen Bao'an Highway (a bidirectional, eight-lane roadway with an entire-line truck ban and a speed limit of $80 \mathrm{~km} / \mathrm{h}$ ). 
TABLE 2: Characteristics of primary paralleled and connected roadways related to GSCE-SS.

\begin{tabular}{lcccccc}
\hline Route code $i$ & Route name & Grades & $\begin{array}{c}\text { Speed limit } \\
(\mathrm{km} / \mathrm{hr})\end{array}$ & $\begin{array}{c}\text { Bidirectional lanes } \\
\text { count }\end{array}$ & $\begin{array}{c}\text { Design capacity } \\
(\mathrm{pcu} / \mathrm{hr})\end{array}$ & $\begin{array}{c}\text { Unidirectional spare } \\
\text { capacity }(\%)(\mathrm{pcu} / \mathrm{hr})\end{array}$ \\
\hline 1 & GSCE-SS & Provincial & 100 & 8 & 14400 & - \\
2 & Bao'an Highway & Urban & 80 & 8 & 12000 & $900(15 \%)$ \\
3 & G107 & National & 100 & 8 & 14400 & $1080(15 \%)$ \\
4 & GSE & National & 120 & 6 & 10800 & $1080(20 \%)$ \\
0 & Outer Ring Highway & Urban & 100 & 6 & 10000 & $1250(25 \%)$ \\
\hline
\end{tabular}

(ii) The G107 (Shenzhen Segment, a bidirectional, eightlane roadway with a speed limit of $100 \mathrm{~km} / \mathrm{h}$ ).

(iii) The Guang-Shen Expressway (GSE, G15, a bidirectional, six-lane roadway with a speed limit of $120 \mathrm{~km} / \mathrm{h})$.

4.3.2. Connected Roadways and Critical Control Nodes. The Bao'an expressway and the GSE are both directly connected to the GSCE-SS by Fuyong interchange and Weiyuan interchange, respectively. The G107 does not have a direct intersection with GSCE-SS, but intersects with a connected roadwayShenzhen Outer Ring Highway (SORH, a bidirectional, sixlane expressway). The control node in which the GSCE-SS intersected with SORH is Tianyuan interchange, which is also the demarcation point between the Dongguan Segment (GSCE-DS) and Shenzhen Segment (GSCE-SS).

Characteristics of selected paralleled and connected roadways related to GSCE-SS are shown in Table 2. Figure 4 presents the map of paralleled roadways, connected roadways, and critical control nodes mentioned above.

4.4. Classification of Rainfall Density. In the United States, the National Weather Service maintains a record of rain days (rain day is when at least $0.25 \mathrm{~mm}$ ( 0.01 inches) of rainfall is recorded during a $24 \mathrm{~h}$ period) during the year for 284 sites throughout the country. Data have been compiled at all sites for at least 10 years and at many sites for as long as 50 years [17]. The vast majority of existing studies [10, 12] involving rainfall intensity categories make $0.25 \mathrm{~mm}$ ( 0.01 inches) the lower bound of the "light rain," and they also consistently classified the rainfall intensity as follows:

(i) No rain (less than 0.01 inches/hr, i.e., $0.25 \mathrm{~mm} / \mathrm{hr}$ ).

(ii) Light rain (0.01 to 0.25 inches/hr, i.e., 0.25 to $6.4 \mathrm{~mm} /$ hr).

(iii) Heavy rain (greater than 0.25 inches/hr, i.e., $6.4 \mathrm{~mm} /$ hr).

However, considering the huge different effects of geographic and meteorological conditions on rainfall intensity, using the classification in US will lead to discrepancy in China, especially for the regions of drippy weather like Shenzhen.

The China Meteorological Administration (CMA) released new "Meteorological Disaster Warning Issuing Schemes (MDWIS) by the Central Meteorological Observatory (CMO)" in 2010, but parts of provinces in China still continue to use the MDWIS released by CMA in 2007, considering their own meteorological characteristics and the particular categories in version 2007.

Classification and description of rainfall density in the Meteorological Disaster Warning Issuing Schemes (version 2007) are shown in Table 3. For example, the CMO or the regional meteorological administration will release "BLUE" warning of rain storm under the circumstance that the precipitation within future 12 hours will be up to over 50 millimeters, or it has already been up to over 50 millimeters and the rain may continue. So it indicates that the precipitation rate less than $4.2 \mathrm{~mm} / \mathrm{hr}$ will not trigger the MDWIS, just like the fact that the precipitation rate less than $0.25 \mathrm{~mm} / \mathrm{hr}$ is recorded as "no rain" in the aforementioned American studies.

4.5. Traffic Control System. Freeway management techniques can be summarized as two broad strategies: capacity management and demand management. Capacity management seeks maximizing throughput rate and improving the level of traffic service, whereas demand management attempts to reduce the quantity of vehicular travel [18]. The weather responsive management involves recurring congestion, which usually derives from overloading: traffic demand approaching or exceeding capacity-which results from unrestrained entrance ramp access, particularly during peak periods. As traffic densities exceed approximately 50 vehicles/mile/lane, overloading occurs on the freeway mainline. Demand management techniques consist of entrance ramp control, exit ramp control, mainline control, and priority control and so on [18].

4.5.1. Entrance Ramp Control (ERC). The entrance ramp control (ERC) strategy commonly used includes ramp enclosure and ramp metering. Ramp enclosure is implemented infrequently, because of the strong public opposition it usually draws [18], and the ramp metering strategy is considered in this study. Compared with the six-grade categories $(\mathrm{A}-\mathrm{F})$ of freeway LOS in the US, four grades (1-4) exist in Chinese freeway LOS. Table 4 and Figure 6(a) present a rough grading schedule of freeway LOS in China and the implementation criteria of ERC strategy and suggested implemented scenarios for GSCE-SS, respectively.

4.5.2. Mainline Control. This involves the regulation, warning, and guidance of traffic on the freeway mainline itself 


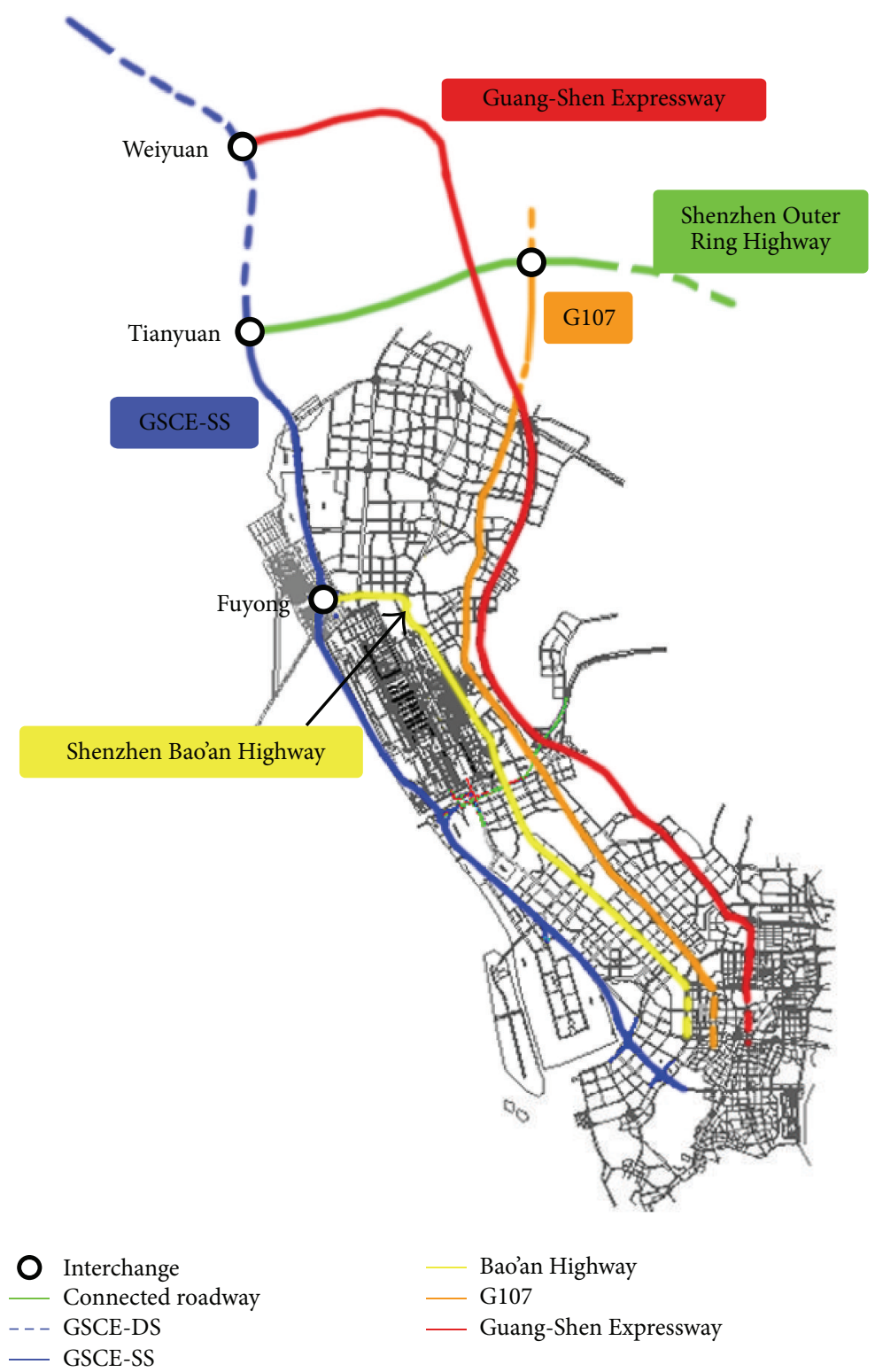

FIGURE 4: The map of paralleled roadways, connected roadways, and critical control nodes for GSCE-SS.

in order to improve safety and increase operational efficiency. The most common techniques of mainline control are motorist information systems, variable speed control, lane closure, and reversible lane control $[19,20]$.

For those vehicles which are already running on the GSCE-SS and are under the influence of the heavy rainstorm or other adverse weather invents, mainline control strategies mean that their operation safety can be safeguarded by the measures such as warning from variable message signal (VMS), police patrol, and guidance signs.

As a result of the negative effect of rainstorm, crashes may occur on the mainline. Once an accident happens, the mainline control here requires the crashes to be efficiently disposed of to recover the capacity of the expressway, avoiding the large-scale queuing and congestion at the upstream of the accident spot. The details of mainline control strategies and implemented scenarios for GSCE-SS are listed in Table 5 and Figure 6(b), respectively.

4.6. CORSIM-Based Modeling for Alternate Route Choice Schemes. The FHWA's Traffic Software Integrated System (TSIS) is an integrated development environment that enables users to conduct traffic operations analysis. Built using component architecture, TSIS is a toolbox that contains tools allowing the user to define and manage traffic analysis projects, define traffic networks and create inputs for traffic simulation analysis, execute traffic simulation models, and interpret the results of those models [21]. Traffic researchers usually call TSIS CORSIM, which is the core calculator inserted in TSIS.

The HGV ratio of the GSCE-SS is assumed to be 5\% in CORSIM. Unidirectional spare capacity $(\mathrm{pcu} / \mathrm{hr}$ ) can 


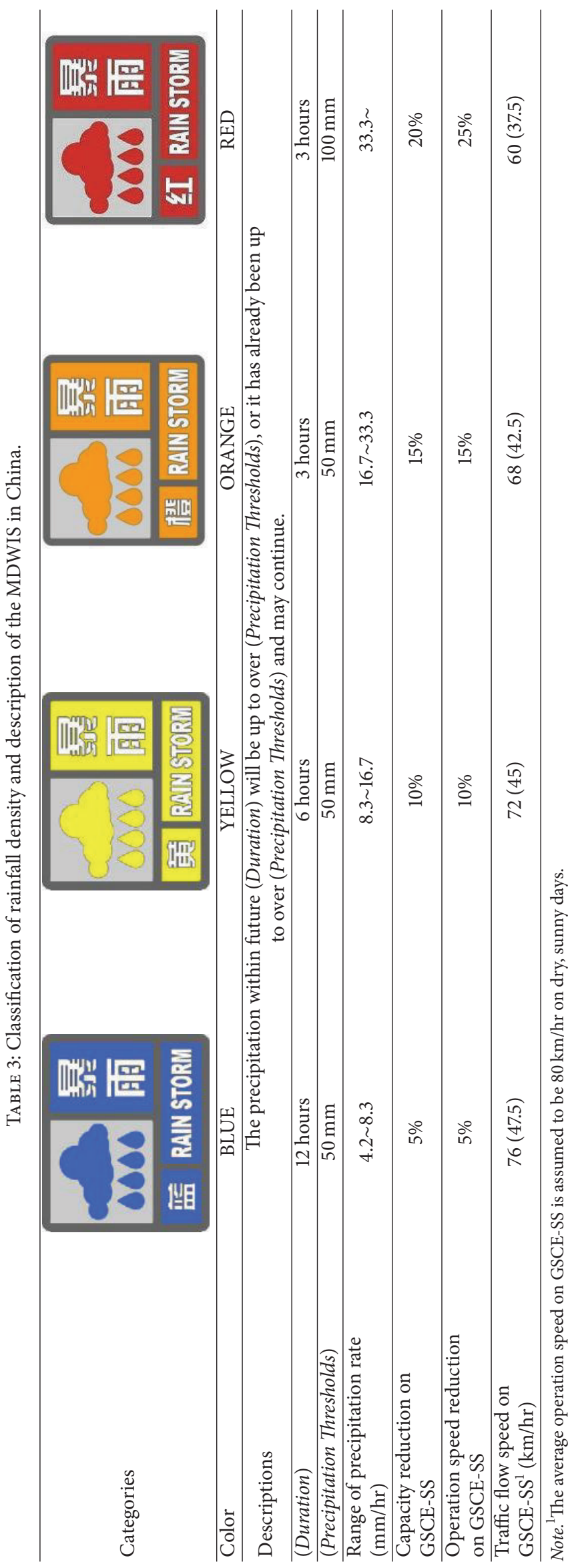


TABLE 4: Grades of freeway LOS in China and the implementation criteria for ERC.

\begin{tabular}{lcccc}
\hline LOS & 1 & 2 & 3 & 4 \\
\hline Operation status of traffic flow & Free flow & Steady flow & Congested flow & Blocked flow \\
\hline Volume to capacity ratio & $v / c \leq 0.3$ & $0.3<v / c \leq 0.6$ & $0.6<v / c \leq 0.8$ & $0.8<v / c \leq 1.0$ \\
\hline Description of LOS & Pretty good & Good & General & Low \\
\hline The ERC strategy & NA & NA & Should be considered or implemented & Should be implemented \\
\hline \multicolumn{2}{l}{ Descriptions of the ERC strategy utilized in GSCE-SS } & Grade B & Grade A
\end{tabular}

Grade B: consider banning hazardous material vehicles, buses, container trucks, and motorcar with disabled taillights from entering the freeway; conduct verbal warnings to drivers to turn on clearance lamps and hazard warning lamps, to keep the space, and to navigate with caution.

Grade A: ban hazardous material vehicles, buses, container trucks, and motorcars with disabled taillights from entering the freeway; conduct compulsive requirements to drivers to turn on clearance lamps and hazard warning lamps, no overtaking, to keep the space, and to navigate with caution.

TABLE 5: The schemes grades and disposal programs of the mainline control strategies.

\begin{tabular}{ll}
\hline Schemes grades & Disposal programs \\
\hline General & (1) Release the message "navigate with caution" to drivers on VMS. \\
(2) The traffic policemen drive to conduct patrol and guidance. \\
(3) Place a warning mark at the upstream of accident spot, and appoint policemen to dredge the flow. \\
(1) Release the message "navigate with caution" to drivers on VMS; staff at toll station spread cards printed with \\
driving tips on adverse weather days. \\
(2) Once the dispatching command center receives crashes reports, it will dispatch the traffic policemen to \\
dispose of crashes. \\
(3) The policemen set up a warning zone and place a warning mark at the upstream of accident spot. Accident \\
causes and property damage amount should be recorded and dredge the congested flow. \\
(4) Reversible lane control strategy can be used to expand the capacity of some direction under extreme \\
conditions.
\end{tabular}

accommodate flow transformed from GSCE-SS for route $i$ under the warning level $j$ which can be calculated by the following equation:

$$
C_{i j}=\frac{1}{2} N_{i} C_{0 i}\left(1-\rho_{j}\right) \eta_{i j}
$$

where $i$ is alternate routes code, $i=0 \sim 4$ (see Table 2); $j$ : under the warning level $j, j=1 \sim 4 . j=1$ if BLUE warning, 2 if YELLOW warning, and by this analogy; $C_{i j}$ is unidirectional spare capacity (pcu/hr) which can accommodate flow transformed from GSCE-SS for route $i$ under the warning level $j ; N_{i}$ is bidirectional lanes count of route $i ; C_{0 i}$ is designed capacity (pcu/hr) per lane of route $i ; \rho_{j}$ is capacity reduction (\%) under warning level $j ; \eta_{i j}$ is spare capacity (\%) which can be used to accommodate flow transformed from GSCE-SS for route $i$ under the warning level $j$.

The simulation model of the GSCE-SS was developed based on existing data (i.e., roadway geometrics and traffic volume). The parameters for behavior models were calibrated using total travel time as the calibration measure [22], as presented in Table 6. Besides, the headway parameter of the models increased as the rise of the warning grades (i.e., from BLUE to RED). During the calibration process, the one-hour simulation with 60 intervals was conducted with ten repetitions to account for the stochastic nature of the simulation. The operation process of CORSIM simulation for a fixed $j$ is described as the flow chart Figure 5 shows (the original value of $i$ equals one). Warning overflow means the demand exceeds capacity (i.e., $v / c>1$ ) and congestion occurs. For instance, if the value of $i$ ends as 3 , it indicates that the given volume $Q$ is recommended to take Bao'an Highway $(i=2)$ and G107 $(i=3)$ as alternate routes on the premise of a given rainstorm warning grade $j$, which results as an "Orange Square" dot in Figure 6(c).

4.7. Information Release Schemes. "The Procedure Stipulation for Freeway Traffic Emergency Management" issued by the Ministry of Public Security of the People's Republic of China in December, 2008, clearly expounded the regulation of the "information-reporting and releasing" in the process of freeway traffic emergency management.

Once the expressway/city is attacked by typhoon or rainstorm, the public security department will release information reported from various departments to the public. The information will include adverse weather warning grades released by Local Meteorological Administration (LMA) or CMA, the current condition of the highway, the traffic control and management strategies taken by the government, and so on. The information released should be timely, accurate, objective, and comprehensive. The emergency management and measures of traffic control should be released by the means of live reports or press conference by the provincial TV, broadcast, radio, and mobile phone terminals (e.g., short messages). What is more, the Dispatching Command Center (DCC) of Shenzhen expressway department must broadcast the scrolling traffic management measures to the motorists 
TABLE 6: Calibrated behavior parameters for the alternate routes choice simulation model by CORSIM.

\begin{tabular}{lcc}
\hline Parameters & Default & Calibrated \\
\hline Lag acceleration (s) & 0.3 & 1 \\
Lag deceleration (s) & 0.3 & 0.5 \\
Pitt car following constant (ft) & 10 & 4 \\
Time to complete a lane change maneuver (s) & 2 & 10 \\
Gap acceptance & 3 & 3 \\
Percent of drivers yielding the right-of-way to lane-changing vehicles attempting to merge ahead (\%) & 20 & 0.5 \\
Multiplier for desire to make a discretionary lane change & 0.4 \\
Advantage threshold for discretionary lane change & 0.2 \\
Minimum interval for generation of vehicles (s) & 1.6 \\
Leader's max. deceleration as perceived by its follower (feet/sec ${ }^{2}$ ) & 15 \\
\hline
\end{tabular}

TABLE 7: Information release schemes for GSCE-SS under rainstorm conditions.

\begin{tabular}{lccc}
\hline Schemes & Information release department & Means or media grades & Specific content of information \\
\hline C & $\begin{array}{c}\text { The operation management } \\
\text { corporation of GSCE-SS }\end{array}$ & $\begin{array}{c}\text { VMS, removable traffic signs on } \\
\text { GSCE-SS }\end{array}$ & $\begin{array}{c}\text { Weather, roadway conditions, } \\
\text { and traffic control schemes }\end{array}$ \\
\hline B & $\begin{array}{c}\text { DCC of Shenzhen expressway } \\
\text { department }\end{array}$ & $\begin{array}{c}\text { Local media and urban, public } \\
\text { traffic electronic screen }\end{array}$ & $\begin{array}{c}\text { Traffic condition and advise to } \\
\text { change routes or suffer } \\
\text { congestion and delay }\end{array}$ \\
\hline A & DCC of Guangdong expressway \\
department & Provincial media & $\begin{array}{c}\text { Real-time expressway control } \\
\text { schemes to the whole province }\end{array}$ \\
\hline
\end{tabular}

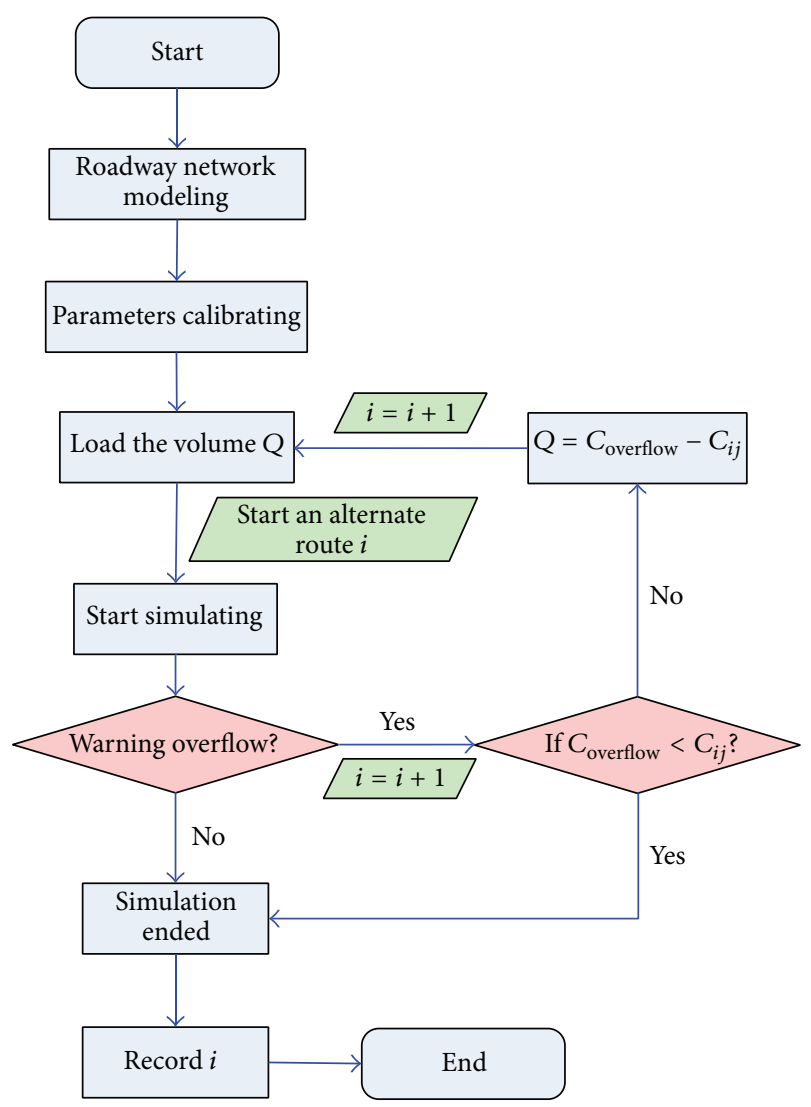

FIGURE 5: Flow chart for the operation process of CORSIM simulation for fixed $j$ and $Q$ to confirm an alternate route scheme.

throughout the whole highway. After the adverse weather invent fades away, the emergency management measures and the warnings should be lifted timely to make traffic return to normal and then release corresponding situations to the society as soon as possible. Information release schemes for GSCE-SS under rainstorm conditions are presented in Table 7. Figure 6(d) gives the information release schemes for GSCE-SS under rainstorm conditions.

\section{Conclusions}

Adverse weather can have a negative effect on the driving safety of motorists and effective management by reducing visibility and road surface friction, lowering vehicle maneuverability, and increasing crash frequency and injury severity. These impacts of adverse weather and its interactions with drivers and roadway on the operation and management of expressway or expressway bridges have drawn the researchers' and managers' attention to develop traffic management frameworks to mitigate the negative influence.

Kinds of adverse weather invents were analyzed together in this study due to their similarity in disaster-causing mechanism. This study developed a traffic management framework for coastal expressway bridges under adverse weather conditions, while the impact of rainfall on the traffic management was further elaborated. The proposed traffic management framework consisted of traffic demand and network analysis, traffic management strategies, and advisory strategies. The Guangshen Coastal Expressway-Shenzhen Segment (GSCESS) was chosen as a case to explore the systematization. Conditions categorized by rainfall intensity and traffic flow were the main precondition to make the management decisions. CORSIM simulator was used to develop the alternate routes choice schemes, providing reference for other sections in the proposed traffic management framework. Maps of (a) ERC strategies; (b) mainline control; (c) alternate routes 


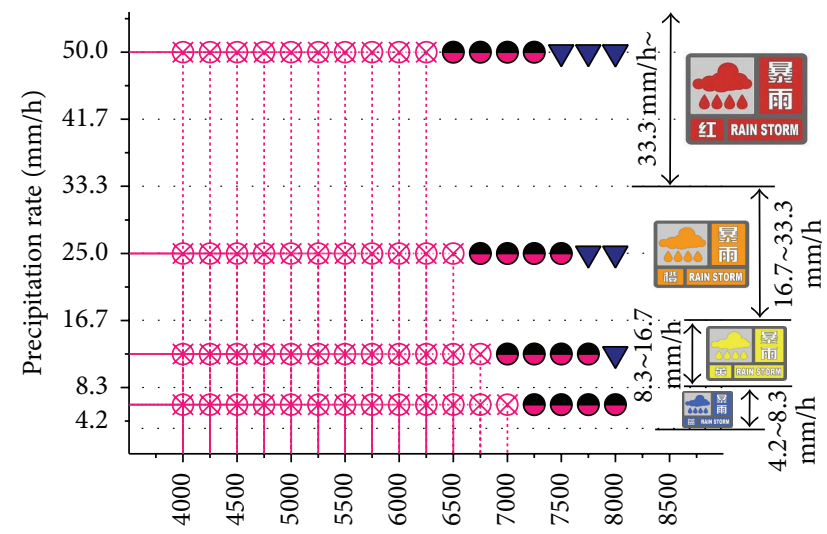

Unidirectional real-time traffic volume (pcu/h)

$\otimes N A$

Grade B

$\nabla$ Grade A

(a) ERC strategies

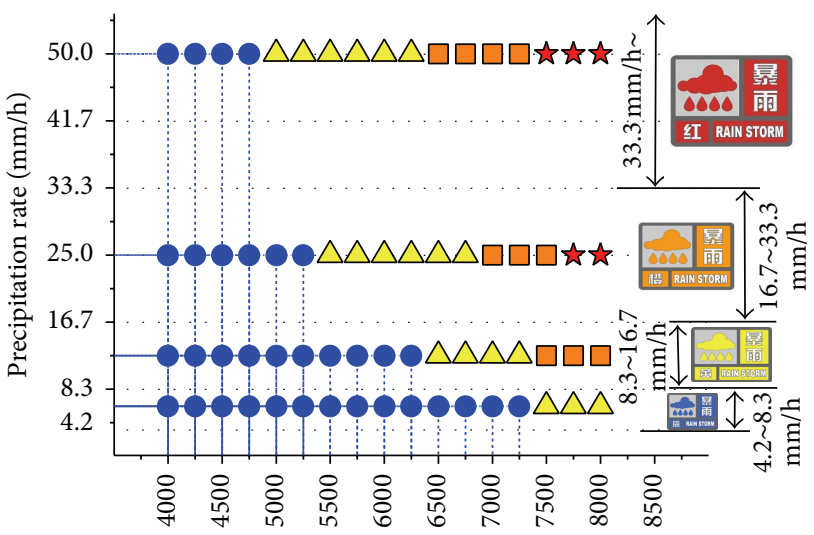

Unidirectional real-time traffic volume (pcu/h)

$\begin{array}{ll}\triangle \text { GSCE-SS } & \square \text { G107 } \\ \triangle \text { Bao'an Highway } & \text { GSE }\end{array}$

(c) Alternate routes choice based on CORSIM

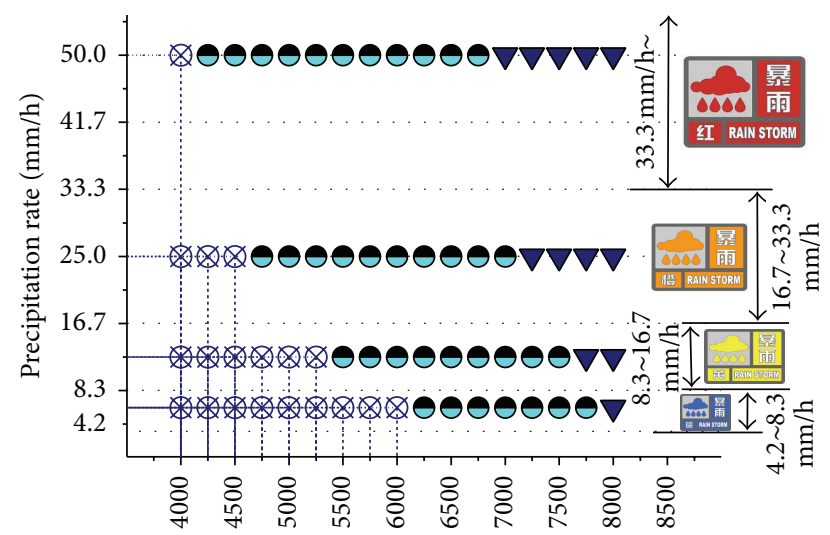

Unidirectional real-time traffic volume (pcu/h)

$\otimes$ NA

$\ominus$ General

$\nabla$ Severe

(b) Mainline control

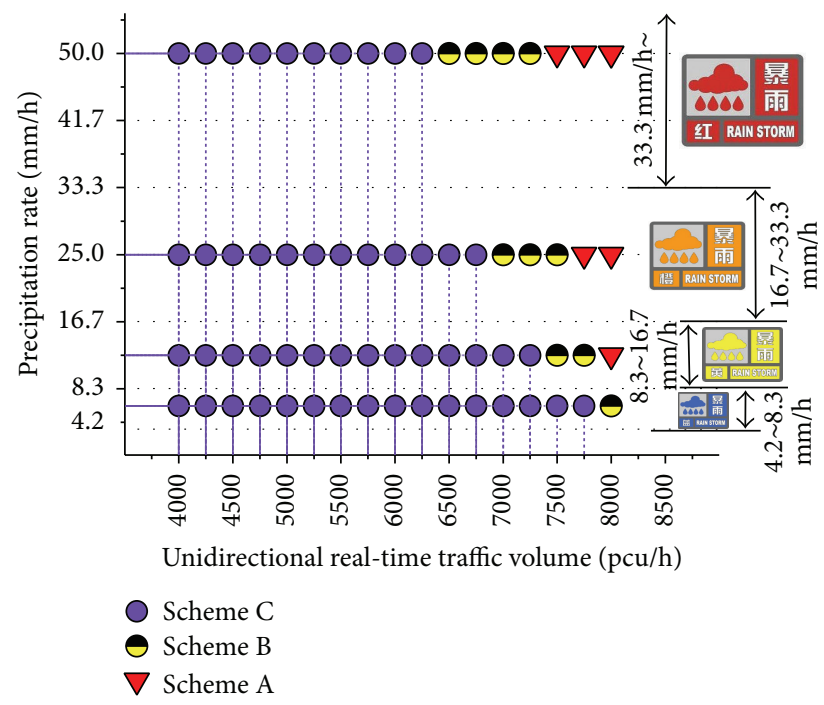

(d) Information release schemes

FIGURE 6: Maps of (a) ERC strategies; (b) mainline control; (c) alternate routes choice; (d) information release schemes, under scenarios of different volume and rainstorm warning grades (BLUE to RED).

choice; (d) information release schemes, under scenarios of different volume and rainstorm warning grades (BLUE to RED) were drawn. Though the data utilized in this study to model the traffic management framework were derived from real roadway network, this framework needs to be further implemented and improved in practice.

\section{Conflict of Interests}

The authors declare that there is no conflict of interests regarding the publication of this paper.

\section{Acknowledgments}

This research is sponsored by the program "The Research on the Key Technology on Safety Operation and Management of the Eight-Lane Long-Span Expressway Bridge under the Coastal Environment," which is a subproject of "The Research on the Key Technology on the Construction of Guang-Shen Coastal Expressway (Shenzhen Segment)" (no. Science and Technology-2011-01-002) conducted by the Ministry of Transportation of Guangdong Province and the program "Research on Disaster Insurance Decision in Area of Transportation Emergency Management," a special fund of social cognition in intersection area of Arts and Science of Shanghai Jiao Tong University.

\section{References}

[1] P. Pisano and L. Goodwin, "Surface transportation weather applications," in Proceedings of the Annual Meeting of the Institute of Transportation Engineers, Federal Highway Administration (FHWA), Mitretek Systems, Philadelphia, Pa, USA, August 2002. 
[2] P. A. Pisano and L. C. Goodwin, "Research needs for weatherresponsive traffic management," Transportation Research Record: Journal of the Transportation Research Board, vol. 1867, pp. 127-131, 2004.

[3] A. J. Khattak and A. De Palma, "The impact of adverse weather conditions on the propensity to change travel decisions: a survey of Brussels commuters," Transportation Research Part A: Policy and Practice, vol. 31, no. 3, pp. 181-203, 1997.

[4] W. Gillam and R. Withill, "UTC and inclement weather conditions," in Proceedings of the Institute of Electrical and Electronics Engineers Conference, pp. 85-88, Leicestershire County Council \& University of Nottingham, 1992.

[5] Mitretek Systems, "Analysis of Weather Impacts on Traffic Flow in Metropolitan Washington, DC," in Proceedings of the American Meteorology Society Annual Meeting, 2003.

[6] J. Perrin and P. Martin, "Modifying signal timing during inclement weather," in Proceedings of the Annual Meeting of the Institute of Transportation Engineers, University of Utah Traffic Lab, Philadelphia, Pa, USA, August 2002.

[7] TRB, Highway Capacity Manual 2000, Transportation Research Board, 2000.

[8] R. Lamm, E. M. Choueiri, and T. Mailaender, "Comparison of operating speeds on dry and wet pavements of two-lane rural highways," Transportation Research Record, vol. 1280, 1990.

[9] A. T. Ibrahim and F. L. Hall, "Effect of adverse weather conditions on speed-flow-occupancy relationships," Transportation Research Record, no. 1457, pp. 184-191, 1994.

[10] B. L. Smith, K. G. Byrne, R. B. Copperman, S. M. Hennessy, and N. J. Goodall, "An investigation into the impact of rainfall of freeway traffic flow," in Proceedings of the 83rd Annual Meeting of the Transportation Research Board, Washington, DC, USA, January 2004.

[11] G. L. Ries, Impact of Weather on Freeway Capacity, Minnesota Department of Transportation, Office of Traffic Engineering, Minneapolis, Minn, USA, 1981.

[12] M. Agarwal and T. H. Maze, "Reginald souleyrette. Impacts of weather on urban freeway traffic flow characteristics and facility capacity," in Proceedings of the Mid-Continent Transportation Research Symposium, Ames, Iowa, USA, August 2005.

[13] R. M. Alfelor, Weather Responsive Traffic Management-Real Solutions for Serious Traffic Problems, FHWA-JPO-09-035, U.S. DOT, Washington, DC, USA, 2009.

[14] D. Gopalakrishna, C. Cluett, F. Kitchener, and K. Balke, "Developments in weather responsive traffic management strategies," US Final Report FHWA-JPO-11-086, 2011.

[15] FHWA Road Weather Management Program and US Department of Transportation, Weather Responsive Traffic Management Strategies-New Approaches to Improve Safety and Mobility, FHWA-JPO-11-093, US Department of Transportation, 2011.

[16] R. S. Ju, A. R. Cook, and T. H. Maze, "Techniques for managing freeway traffic congestion," Transportation Quarterly, vol. 41, no. 4, pp. 519-537, 1987.

[17] M. Kyte, Z. Khatib, P. Shannon, and F. Kitchener, "Effect of weather on free-flow speed," Paper 01-3280, Transportation Research Board, 2001.

[18] S. A. Ahmed, "Urban freeway traffic management technology," Journal of Transport Engineering, vol. 112, no. 4, pp. 369-371, 1986.

[19] Federal Highway Administration, Traffic Control Systems Handbook, US Department of Transportation, Washington, DC, USA, 1976.
[20] H. J. Payne and A. D. May, Control of Mainline Freeway and Freeway-Freeway Connectors for Bottleneck Alleviation, Federal Highway Administration, U.S. Department of Transportation, Washington, DC, USA, 1982.

[21] TSIS User Guide by Mctrans, University of Florida, Gainesville, Fla, USA, 2008.

[22] D. Wei, Effect of ramp combination type and distance to average speed of combination area in urban freeway [M.S. thesis], Shanghai Jiao Tong University, Shanghai, China, 2013. 


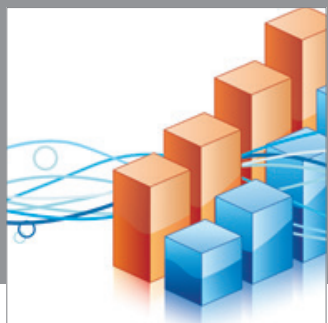

Advances in

Operations Research

mansans

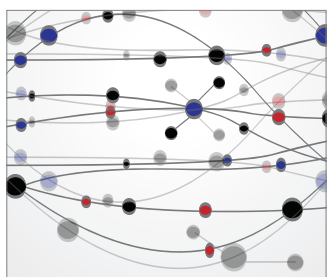

The Scientific World Journal
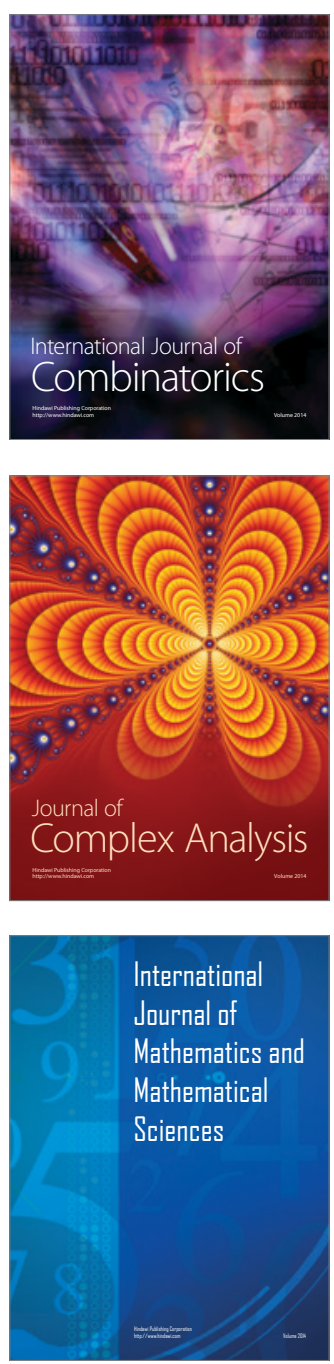
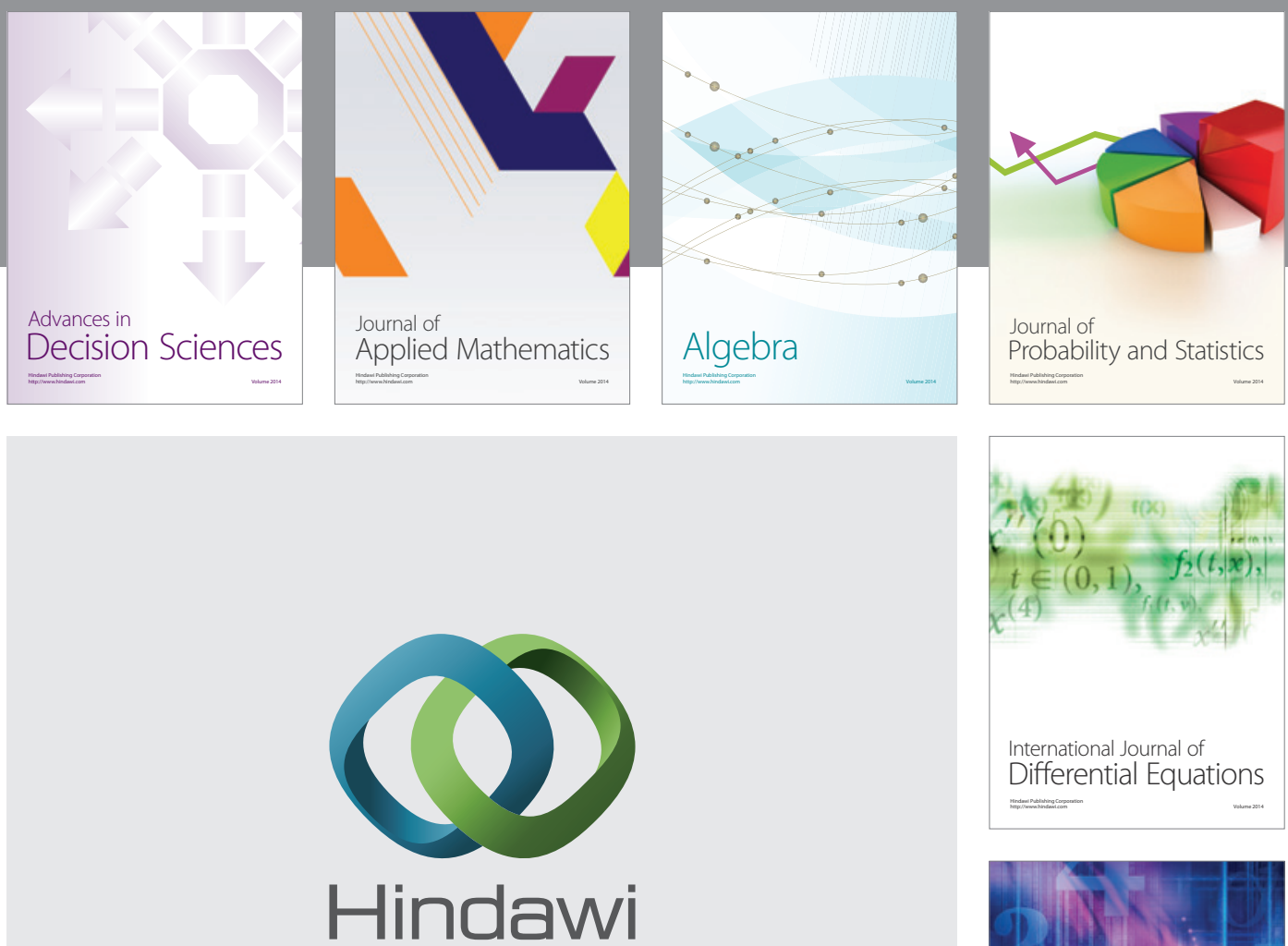

Submit your manuscripts at http://www.hindawi.com
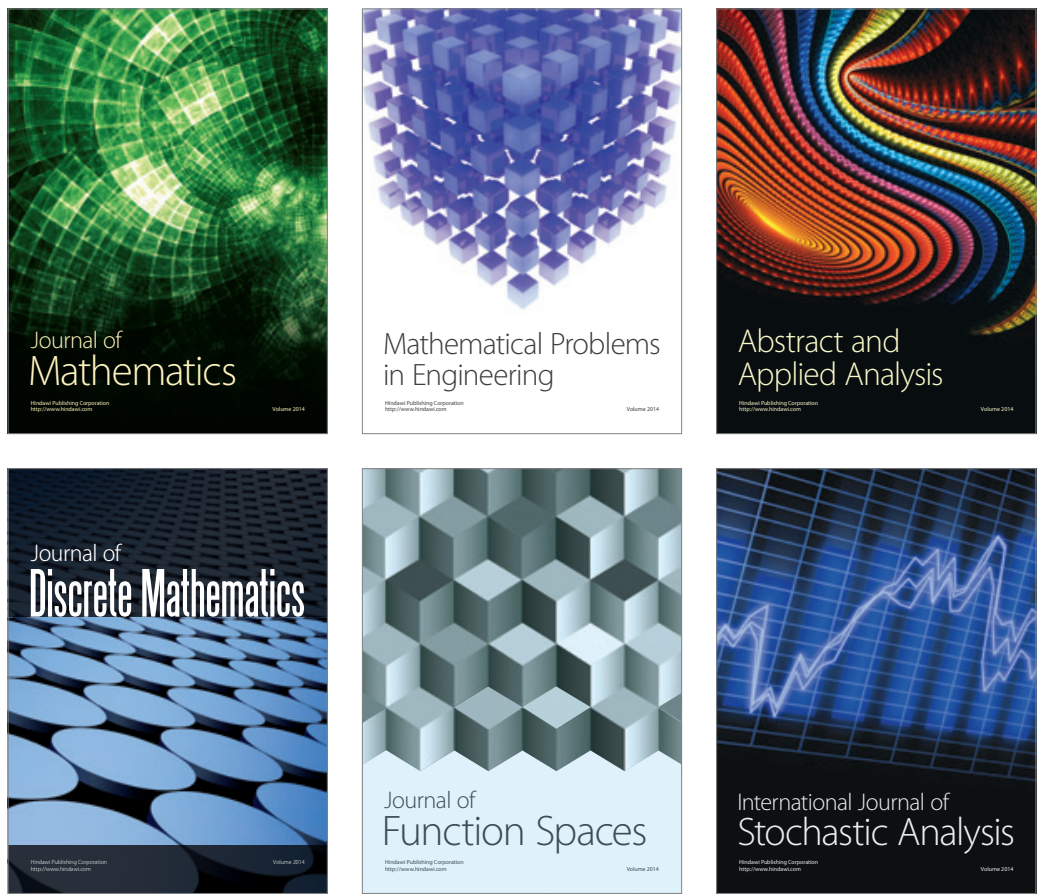

Journal of

Function Spaces

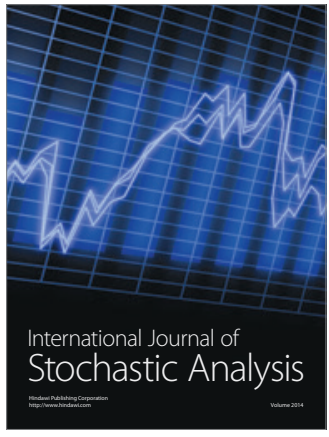

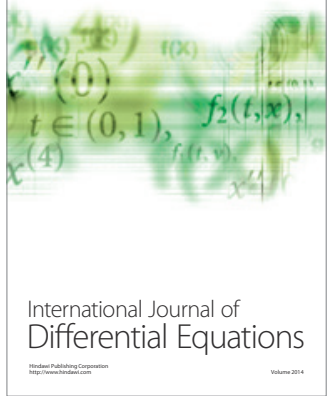
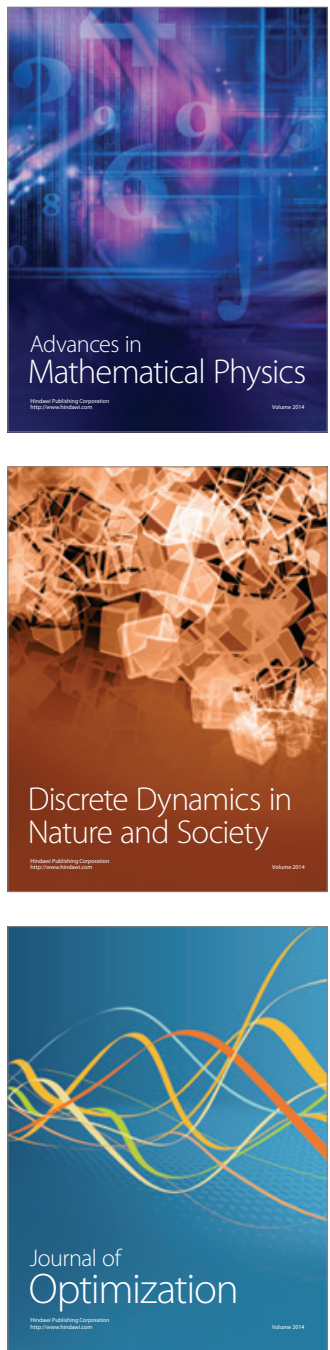